\title{
VULNERABILITY INDEX ASSESSMENT USING NEURAL NETWORKS (VIANN): A CASE STUDY OF NICOSIA, CYPRUS
}

\author{
H. Dindar ${ }^{\text {a, b*, K. Dimililer }}{ }^{\text {c }}$, Ö. C. Özdağ ${ }^{\text {d }}$, C. Atalar ${ }^{\text {bee }}$, M. Akgün ${ }^{\text {f }}$, A. Özyank1 ${ }^{\text {b,e }}$ \\ ${ }^{a}$ Graduate School of Natural and Applied Sciences, Dokuz Eylül University, İzmir, Turkey - hilmi.dindar@ogr.deu.edu.tr \\ ${ }^{b}$ NEU Earthquake and Soil Research and Evaluation Center, Near East University, Nicosia, North Cyprus, Mersin 10, Turkey - \\ (hilmi.dindar, arif.ozyanki, cavit.atalar)@neu.edu.tr \\ ${ }^{c}$ Dept. of Electrical and Electronic Engineering, Near East University, Nicosia, North Cyprus, Mersin 10, Turkey - \\ kamil.dimililer@neu.edu.tr \\ d Aegean Implementation and Research Center, Dokuz Eylül University, İzmir, Turkey - cevdet.ozdag@ deu.edu.tr \\ ${ }^{\mathrm{e}}$ Dept. of Civil Engineering, Near East University, Nicosia, North Cyprus, Mersin 10, Turkey - (cavit.atalar, \\ arif.ozyanki)@neu.edu.tr \\ ${ }^{\mathrm{f}}$ Dept. of Geophysical Engineering, Dokuz Eylül University, İzmir, Turkey - mustafa.aKgun@ deu.edu.tr
}

KEY WORDS: Vulnerability Index, Microtremor, Back Propagation Neural Networks, Sensitivity Zones, Nakamura Method

\begin{abstract}
:
Many scholars have used microtremor applications to evaluate the vulnerability index. In order to reach fast and reliable results, microtremor measurement is preferred as it is a cost-effective method. In this paper, the vulnerability index will be reviewed by utilization of microtremor measurement results in Nicosia city. 100 measurement stations have been used to collect microtremor data and the data were analysed by using Nakamura's method. The value of vulnerability index $\left(\mathrm{K}_{\mathrm{g}}\right)$ has been evaluated by using the fundamental frequency and amplification factor. The results obtained by the artificial neural network (ANN) will be compared with microtremor measurements. Vulnerability Index Assessment using Neural Networks (VIANN) is a backpropagation neural network, which uses the original input microtremor Horizontal Vertical Spectrum Ratio (HVSR) spectrum set. A 3-layer back propagation neural network which contains 4096 input, 28 hidden and 3 output neurons are used in this suggested system. The output neurons are classified according to acceleration sensitivity zone, velocity zones, or displacement zones. The sites are classified by their vulnerability index values using binary coding: $\left[\begin{array}{lll}1 & 0 & 0\end{array}\right]$ for the acceleration sensitive zone, $\left[\begin{array}{llll}0 & 1 & 0\end{array}\right]$ for the velocity sensitive zone, and $\left[\begin{array}{lll}0 & 0 & 1\end{array}\right]$ for the displacement sensitive zone.
\end{abstract}

\section{INTRODUCTION}

Earthquake is a common natural disaster, which can directly affect human lives. Earthquakes exemplify a massive natural hazard, resulting in casualties and major damage to buildings and businesses. In order to protect human lives and their properties, various scholars indicate the need for a complete research on earthquake's risks by estimating the ground motions (Choobbasti et al., 2014).

The study area was conducted in Northern Nicosia within an area of $110 \mathrm{~km}^{2}$. Within these microtremor studies we have used Nakamura's method, which is a HVSR method, whereas fundamental frequency, amplification factor, and finally vulnerability index $\left(\mathrm{K}_{\mathrm{g}}\right)$ were derivate from both these two parameters (Figure 1).

Nicosia is the largest city of Cyprus, has been preferred to carry out the measurements. The reason why Nicosia has been preferred is that it is an ancient walled city that is located at the intersection of water supply such as the largest river of Kanlidere (Pedios). Nicosia has also been the capital of Cyprus for centuries. During the 1995 Cyprus earthquake the damage to buildings in North Cyprus were more severe on soft soils around the ancient city kingdoms of Soli (Atalar, 1999).

* Corresponding author
The problems that reveal in construction depend on soft soil layers and the features of soil such as compressibility, shear modulus etc., occurs within nature of the over consolidated swelling soils of Northern Cyprus (Atalar and Das, 2009).

Microseismic noises are defined as microtremors. These are inactive ground motions with displacement amplitudes that can be signified by seismograph with high amplification. Many scholars use the Horizontal Vertical Spectral Ratio (HVSR) Technique to observe soil properties that affect the vulnerability of sites to earthquake (Rezaei and Choobbasti, 2014; Nakamura, 1989; Paudyal et al., 2013; Fnais et al., 2010; Beroya et al., 2009; Jiyang et al., 2016; Stanko et al., 2017; Gosar, 2007; Mucciarelli et al., 2001; Pamuk et al., 2017). By utilizing the $\mathrm{H} / \mathrm{V}$ ratio, the soil fundamental period (T0) and the amplification factor $(\mathrm{Ag})$ of the site were determined (Tarabusi and Caputo, 2017; Stanko et al., 2017; Hardesty et al., 2010; Özdağ et al., 2015). By utilizing the $\mathrm{H} / \mathrm{V}$ ratio, the soil fundamental period $\left(\mathrm{T}_{0}\right)$ and the amplification factor $\left(\mathrm{Ag}_{\mathrm{g}}\right)$ of the site were determined (Stanko et al., 2017; Tarabusi and Caputo, 2017; Hardesty et al., 2010; Özdağ et al., 2015) 
Artificial neural networks is a popular field that is applied in various applications to make categorization (Dimililer, 2012; Dimililer, 2013; Dimililer et al., 2016; Dimililer et al., 2017; Tavakoli and Kutanaei, 2014).

Neural computing directly uses field and experimental data without simplifying assumptions. This approach is a tool for graphical computing and used in parallel environment for nonalgorithmic method, which is capable of executing massive computations. In data processing, the back-propagation neural networks, specific learning algorithm is used to update the weightings of each layer in considering the errors from the network output. As a result, back propagation neural networks frequently applied to various types of engineering (Dimililer et al., 2017; Adeli, 2001).

It has been demonstrated that, the artificial neural networks (ANN) with different inputs including thickness, shear wave velocity, etc. were trained at more than 18 boreholes in their study area (Choobbasti et al., 1989). Then, the trained ANN predicts the fundamental frequency and the output results had been compared with microtremor measurement. The authors indicated that three neural networks models with different inputs such as epicentral distance, focal depth, and magnitude of the earthquake records. The output results were compared with available nonlinear regression analysis in their study (Kert and Chu, 2002). According to their opinion the present neural networks model has better results than the others. For instance, calculation results were sufficient and closer to the actual seismic records.

Kerh and Chu (2002) explained BPNN as a gradient descent method where learning rate $\eta$ and the momentum factor $\alpha$ known as the parameters. In the iterative calculation process, these parameters were introduced.

In 2006, Esposito et al. proposed a supervised classification system using the trained subset data and it has been tested on another set of data, which is not used during the training stage. The automatic system was able classify the events in the test set for both explosion-quake/landslide and explosionquake/microtremor couples with a ratio of $99 \%$, landslide/microtremor discrimination of $96 \%$, and $97 \%$ for three-classes of discrimination (landslides/ explosionquakes/ microtremor) correctly. The authors claimed that to determine the intrinsic structure of the data and to test the efficiency of our parametrization strategy, it has been analysed the pre-processed data using an unsupervised neural method. The authors applied this method to the entire dataset composed of landslide, microtremor, and explosion-quake signals.

Gunaydin and Gunaydin (2008) studied the development of the PGA estimation models for North-Western Turkey by using ANN methods. FFBF, RBF and GRNN have been used as three different artificial neural networks models. The results showed that the models of FFBP gave the best prediction performance under the conditions of used data. PGA values of FFBP were modified by the regression analysis in order to improve prediction performance.

\section{METHODOLOGY}

\subsection{Data Acquisition}

It is required to make detailed studies in order to determine earthquake-soil- structure common interaction. In this context, the single station microtremor recordings were taken at nearly 100 different points with a broadband feature and maintained at least 30 minutes record length in Nicosia. In addition to this collected data is processed with using 81,92 seconds length time windows due to observe the variance of amplitude with frequency at low values and for each measurement points maximum amplitude and frequency values are determined by using Nakamura approach.

Microtremor measurement was carried at 100 stations in the wider Nicosia area during 2014-2015. The measurements started in December 2014 and finalised in April 2015. Cyprus is located in the $36 \mathrm{~S}$ zone grid by Universal Transverse Mercator projection. The study was conducted between 3893450 and 3898450 meters latitudes and between 523800 and 542800 meters longitudes in WGS 84 system shown in Figure 1.

Parameters of the method are presented in Table 1. The parameters, such as fundamental frequency $\left(\mathrm{F}_{0}\right)$, predominant period $\left(\mathrm{T}_{0}\right)$, amplitude or the amplification value (HVSR) of the site are given in the data catalogue that is selected for artificial neural network.

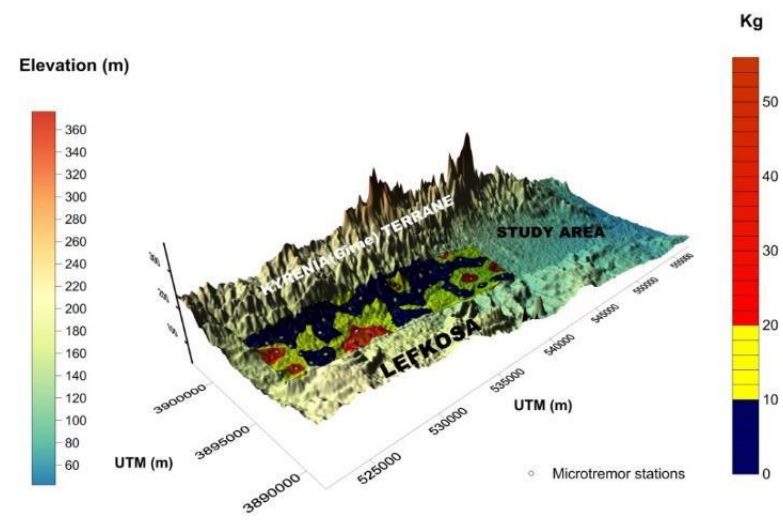

Figure $1 . \mathrm{K}_{\mathrm{g}}$ index values map of study area

\begin{tabular}{|c|c|c|c|c|c|c|}
\hline $\begin{array}{c}\text { Station } \\
\text { No }\end{array}$ & $\begin{array}{c}\text { UTM } \\
\mathrm{X}(\mathrm{m})\end{array}$ & $\begin{array}{c}\text { UTM } \\
\mathrm{y}(\mathrm{m})\end{array}$ & $\begin{array}{c}\mathrm{F}_{0} \\
(\mathrm{~Hz})\end{array}$ & $\begin{array}{c}\mathrm{T}_{0} \\
(\mathrm{~s})\end{array}$ & HVSR & $\mathrm{K}_{\mathrm{g}}$ \\
\hline D18 & 536800 & 3896450 & 8,0 & 0,124 & 1,2 & 0,2 \\
\hline D26 & 537800 & 3895450 & 6,0 & 0,167 & 2,58 & 1,1 \\
\hline D30 & 538800 & 3898450 & 5,8 & 0,174 & 1,39 & 0,3 \\
\hline D35 & 538800 & 3893450 & 12,2 & 0,081 & 2,39 & 0,5 \\
\hline E3 & 540800 & 3896450 & 7,3 & 0,136 & 8,01 & 8,8 \\
\hline E4 & 540800 & 3895450 & 4,9 & 0,202 & 2,96 & 1,8 \\
\hline K1 & 533800 & 3893450 & 7,3 & 0,137 & 1,42 & 0,3 \\
\hline K58 & 523800 & 3898450 & 9,7 & 0,103 & 3,54 & 1,3 \\
\hline K73 & 527800 & 3897450 & 8,4 & 0,118 & 2,45 & 0,7 \\
\hline K83 & 526800 & 3896450 & 7,1 & 0,141 & 3,62 & 1,8 \\
\hline K86 & 529800 & 3896450 & 4,3 & 0,230 & 3,13 & 2,3 \\
\hline K95 & 527800 & 3895450 & 6,8 & 0,148 & 2,56 & 1,0 \\
\hline K100 & 532800 & 3895450 & 1,2 & 0,813 & 1,68 & 2,3 \\
\hline K102 & 523800 & 3894450 & 10,5 & 0,095 & 1,42 & 0,2 \\
\hline K104 & 525800 & 3894450 & 9 & 0,111 & 2,7 & 0,8 \\
\hline K112 & 533800 & 3894450 & 2,7 & 0,373 & 2,84 & 3,0 \\
\hline K113 & 524800 & 3893450 & 11,2 & 0,089 & 2,34 & 0,5 \\
\hline K121 & 532800 & 3893450 & 3,1 & 0,322 & 3,89 & 4,9 \\
\hline
\end{tabular}

Table 1. Data catalogue which obtained from microtremor single station measurements 


\subsection{Microtremor HVSR Method}

Several studies have been performed for identifying the microtremors (Paudyal et al., 2013; Fnais et al., 2010; Beroya et al., 2009; Jiyang et al., 2016). The ground vibrations as we called microtremors have amplitude values vary between 0.1 and 1 micron and velocity amplitude changing between 0.001 and $0.01 \mathrm{~cm} \mathrm{~s}^{-1}$.Microtremors can be classified in two major groups according to their frequency values: frequency values greater than $1 \mathrm{~Hz}$ (up to $20 \mathrm{~Hz}$ ) known as "short period" which refer to shallow soil layers. The depths can change between 0 to 100 meters, performed with the effects of the local surface sources such as industry machines, wind, and traffic noises. Frequencies lower than $1 \mathrm{~Hz}$ called as "long period microtremor" which refers to deeper soil layers like rigid rock formation and performed with natural forces such as ebb and tide, wind and underground seismic activities. Kanai and Tanaka $(1954,1961)$ are pioneers for investigation of short period microtremors and estimation of the site effect with several studies. Nakamura (1989) the $H / V$ spectral ratio method has widely used for evaluating the effect of soil amplification on the earthquake shaking (Pamuk et al, 2017a) firstly determined microtremor features. Nogoshi and Igarashi (1970) firstly determined this method.

\begin{tabular}{|c|c|c|c|}
\hline \multicolumn{4}{|c|}{ Shear modulus } \\
\hline$(\gamma)$ & $10^{-6}$ & $10^{-4} \quad 10^{-3}$ & $10^{-2}$ \\
\hline $\begin{array}{l}\text { Dynamic } \\
\text { Affect }\end{array}$ & $\begin{array}{l}\text { Wave, } \\
\text { Vibration }\end{array}$ & $\begin{array}{l}\text { Fracturing,Ground } \\
\text { subsidence }\end{array}$ & $\begin{array}{c}\text { Landslide, Compaction, } \\
\text { Liquefaction }\end{array}$ \\
\hline Behaviour & Elasticity & $\begin{array}{c}\text { Elasto- } \\
\text { Plasticity }\end{array}$ & Plasticity(Rupture) \\
\hline
\end{tabular}

Table 2. Soil layer and bedrock layer strain relation (reproduced from Nakamura, 1997).

\subsection{Relation of Vulnerability Index with HVSR Method}

Vulnerability indices are symbolized as " $K$ " derivate from loading of soil surface in time of quakes is proposed as follow. Surface shear strain (loading) $\gamma$ is a common factor for ground identification. Table 2 gives the relation $\gamma$ to ground disasters that had been observed by Ishihara (1978). Non-linear characteristics of the ground are greater than $\gamma \cong 1000 \times 10^{-6}$, resulting large deformation and collapse.

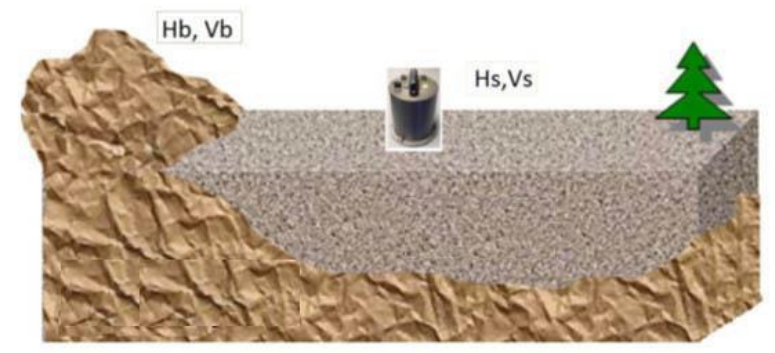

Figure 2. Soil layer and bedrock layer strain relation (reproduced from Nakamura, 1997).
Average strain's shear value, $\gamma$ of soil surface or ground is calculated using the following equation;

$$
\gamma=\frac{A_{g} x D_{s}}{\mathrm{H}}
$$

where, $\quad A g=$ refers to the ground amplification factor,

$$
\mathrm{H}=\text { soil layer thickness, }
$$

$\mathrm{D}_{\mathrm{s}}=$ basement ground seismic displacement (Figure 2).

Imposing $\mathrm{S}$-wave velocity values of bedrock and soil as $\mathrm{Vb}$ and $\mathrm{V}_{\mathrm{S}}$ respectively, $\mathrm{Fg}$ known as pre dominant frequency of the ground is closely expressed as

$$
\mathrm{F}_{\mathrm{g}}=\frac{V_{b}}{4 A_{g} \times H}
$$

Bedrock Acceleration is represented as abed

$$
\mathrm{abed}_{\mathrm{bed}}=\left(2 \pi \mathrm{F}_{\mathrm{g}}\right)^{2} \times \mathrm{D}_{\mathrm{s}}
$$

and $\mathrm{Fg}, \mathrm{Ag}$ and $\mathrm{Vb}$ as follows:

$$
\gamma=\left(A_{g} \times \frac{a_{b e d}}{2 \pi F_{g}}\right)^{2} \times\left(4 A_{g} \times \frac{F_{g}}{V_{b}}\right)=\left(\frac{A_{g}^{2}}{F_{g}}\right) \times\left(\frac{a_{b e d}}{\pi^{2} V_{b}}\right)
$$

Assume that dynamic force efficiency terms as e percentage of static force, then $\gamma$ e effectivity of strain is shown below;

$$
\begin{aligned}
& \gamma_{e}=K_{g}(e) \times a_{b e d} \\
& K_{g}(e)=e \times\left(\frac{A_{g}^{2} / F_{g}}{\pi^{2} V_{b}}\right) \times \frac{1}{100}
\end{aligned}
$$

Considering investigation area, value of $\mathrm{Vb}$ is assumed constant. The value of a point is measured and represented by $\mathrm{K}_{\mathrm{g}}$. This index refers deformation level of the measurement points. Strong or weak sites can be detected with this value for the investigation areas.

Assume that $\mathrm{Vb}$ is $600 \mathrm{~m} / \mathrm{s}$ with $1 /\left(\pi^{2} \mathrm{vb}\right)=1.69 \times 10-6(\mathrm{~s} / \mathrm{cm})$. When e is taken as $60 \%$, then the $\mathrm{K}_{\mathrm{g}}(\mathrm{e}) \cong \mathrm{A}$ \% $\mathrm{Fg}$ and the effective strain can be estimated by multiplying $K_{g}(e)$ value with maximum acceleration of bedrock in $\mathrm{Gal}\left(=\mathrm{cm} / \mathrm{s}^{2}\right)$.

$\mathrm{K}_{\mathrm{g}}$ values were derivate from the measurements in San Francisco Bay after the Loma-Prieta earthquake in 1989. The Figure 3 represents the result from coastline to hillside at marine district. Considering the $\mathrm{K}_{\mathrm{g}}$ values more than 20 , the deformation occurs on the ground and the area has no risk considering the values of $\mathrm{K}_{\mathrm{g}}$ less than 20 (Nakamura, 1997). 


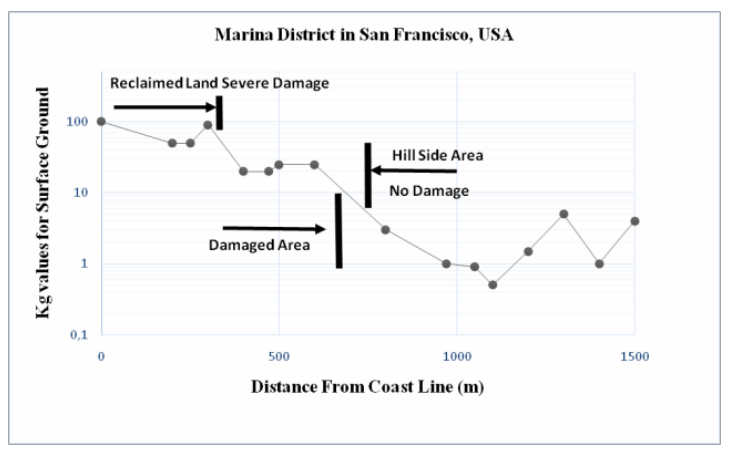

Figure $3 . \mathrm{K}_{\mathrm{g}}$-values derived from microtremor recordings in San Fransisco Bay Area (Nakamura, 1997).

In equation $6, \mathrm{Ag}_{\mathrm{g}}$ represents the maximum value for amplitude and $\mathrm{F}_{\mathrm{g}}$ represents the frequency at $\mathrm{A}_{\mathrm{g}}$ in the whole spectra of QTS.

During an earthquake, the harmonic movement or swinging may result with the soil-structure common interaction and there is a relation with the structure's height. This involvement can be estimate with the peak period value assessment (Ozdag et al., 2016). Figure 4 shows a graphical spectrum for identifying the sensitivity zones, which is obtained from those peak period values revised from Tugsal et al. (2007). The spectrum gives the spectral zones of the earthquake recordings. It refers to the elasticity boundaries of the sites. The first section named as acceleration sensitive zone, and it has a scale between $0,02-0,5$ seconds. It represents the small values and the acceleration effect of the ground will be dominant for this zone. Second section is the velocity sensitive zone and its range is between 0,5 to 3 seconds. It means that the ground motion's velocity effect will be dominant over the values of spectral amplitude that occur during an earthquake. The last section is the displacement sensitive zone and the value interval is between 3 50 seconds. Lastly, the structures that are located in the acceleration sensitivity zone will exhibit an elastic behaviour or will represent rigidity. For instance, a structure that has 15 or more flat (20 at most) will stand in elastic boundaries (that has large period and isolated from earthquake movement).

\section{Sensitivity zones}
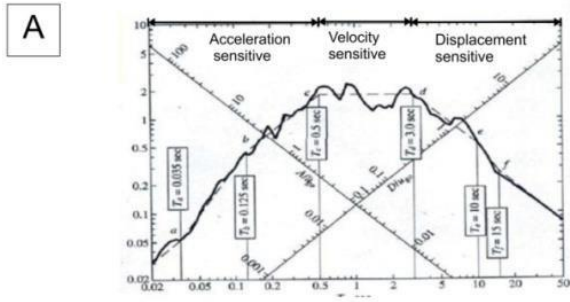

$\mathrm{T}_{\mathrm{n}}(\mathrm{s})$

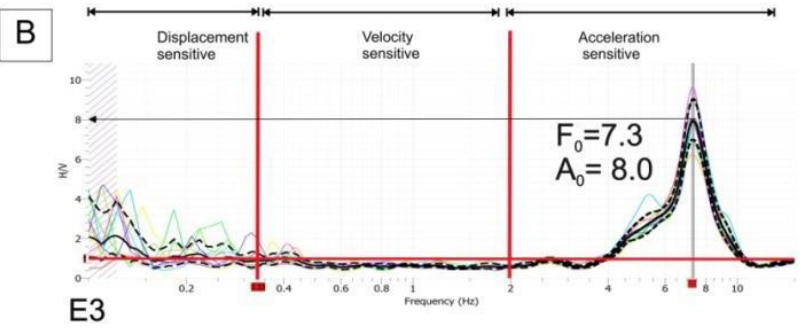

Quasi Transfer Spectrum of E3 station

Figure 4. Determination of the sensitivity zones. A) Three different sensitivity zones of a typical earthquake recording. B) The average spectral ratio sample of HVSR method obtained from station E3.

Microtremor applications were carried out at 100 sites in the study area. Microtremor measurements were applied with the Guralp Systems CMG-6TD seismometer. The record length was approximately 30 minutes with a sampling rate of $100 \mathrm{~Hz}$ at each site. The recorded data can be followed with the Scream 4.5 program. In signal processing phase; intensive artificial disturbance were filtered in a band-pass of $0.05-20 \mathrm{~Hz}$ then they were divided into 81,92 seconds length windows and tapered individually using the Konno-Ohmachi smoothing method. Fast Fourier Transform (FFT) was applied to the amplitude spectra of the three components (Pamuk et al., 2017b). As a result, the average spectral ratio of HVSR method were obtained (Figure 4B). Microtremor measurements were processed and interpreted using GEOPSY software package (www.geopsy.org). Then Quasi Transfer Spectrums (QTS), which is the relation between frequency and amplitude, obtained (Özdağ et al., 2016). Finally, $\mathrm{K}_{\mathrm{g}}$ values computed from the obtained amplitude and frequency values of the each spectrum of 100 different sites (Figure 1).

\subsection{VIANN: Vulnerability Index Assessment using Neural Networks}

This section focuses on utilities and parameters of the proposed system. VIANN is a back propagation neural network that uses the original input microtremor HVSR spectrum set (Figure 5A).

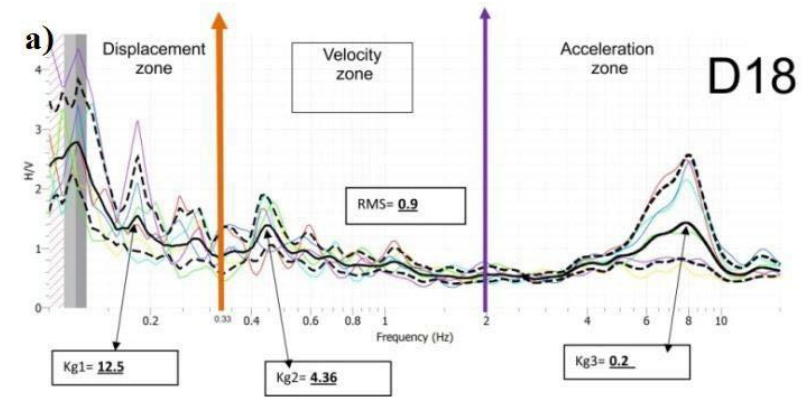

b)

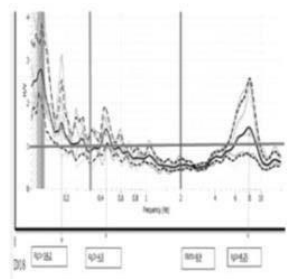

c)

Figure 5. A selected station named as D18 Spectrums. A) HVSR Spectrum; B) 256x256 Original Image; C) 64x64 Resized Image.

\subsubsection{Data Preparation Phase}

Initially, original image has been converted to grayscale in order to minimize the CPU time. The grey colour image contain of pixel intensity between $0-255$ where 0 represents black and 255 is for white. Original image sizes are 256 x 256, whereas 64 × 64 images are preferred considering the processing time (Dimililer and Ilhan, 2016). These two resized images can be found in the Figure 5B and Figure 5C. 


\subsubsection{Neural Networks Phase}

VIANN has a 3-layer back propagation neural network with input, hidden and output neurons having the values of 4096, 28 and 3 respectively. The output neurons are classified according to acceleration sensitivity zone, velocity zones, or displacement zones. The sites classified by their vulnerability index values using binary coding: $\left[\begin{array}{lll}1 & 0 & 0\end{array}\right]$ for the acceleration sensitive zone [ $\left[\begin{array}{lll}0 & 1 & 0\end{array}\right]$ for the velocity sensitive zone, and $\left[\begin{array}{lll}0 & 0\end{array}\right.$ 1] for the displacement sensitive zone. In order to activate the neurons, an activation function is used.

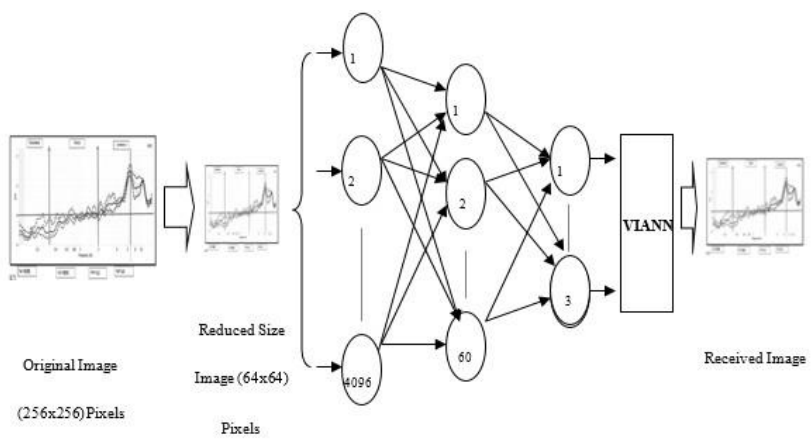

Figure 6. A Recorded Data Spectrum (Site K73) With Neural Network Topology of VIANN.

This function is called sigmoid activation function. The neural network topology is presented in Figure 6. In addition, the final parameters of the VIANN are given in Table 3

\begin{tabular}{|c|c|}
\hline Input Layer Nodes & 4096 \\
\hline Hidden Layer Nodes & 60 \\
Output Layer Nodes & 3 \\
Learning Rate & 0.004 \\
Momentum Rate & 0.5 \\
Minimum Error & 0.002 \\
Iterations & 2042 \\
Training Time & 55 seconds \\
\hline
\end{tabular}

Table 3. Trained neural network final parameters VIANN

\section{DISCUSSIONS ABOUT SUGGESTED SYSTEM}

Figure 7 shows the topology of the suggested BPNN System. Back propagation neural network that is supervised learner property, input - target relationship for training is preferred because this method is simple and easy to implement. Training and generalization are embraced for these two phases. Microtremor database records are organized and shown below:

Microtremor image set for training : 9 images

Microtremor image set for testing set $1: 18$ images

Microtremor image set for testing set $2: 9$ images

Initial random weights for the learning phase are chosen between -0.4 and +0.4 . The learning and momentum rates for the suggested system have been adjusted after several experiments. The value for root mean square error has been chosen as 0.002 and it is considered as sufficient.

In the experimental analysis, a Matlab version of $2012 \mathrm{R} 2$ has been used as software tool, which is installed and executed on a 64-bit virtual operating system. The virtual machine has a 1Gbits connection speed to a super computer. The configuration of the super computer is IBM Blade HS21 XM Intel Xeon $2.33 \mathrm{GHz}$ CPU with 1280 core units. As it is expected from BPNN training phase, a recognition rate of $100 \%$ has been achieved. This proves the robustness, flexibility, and speed of this intelligent system.

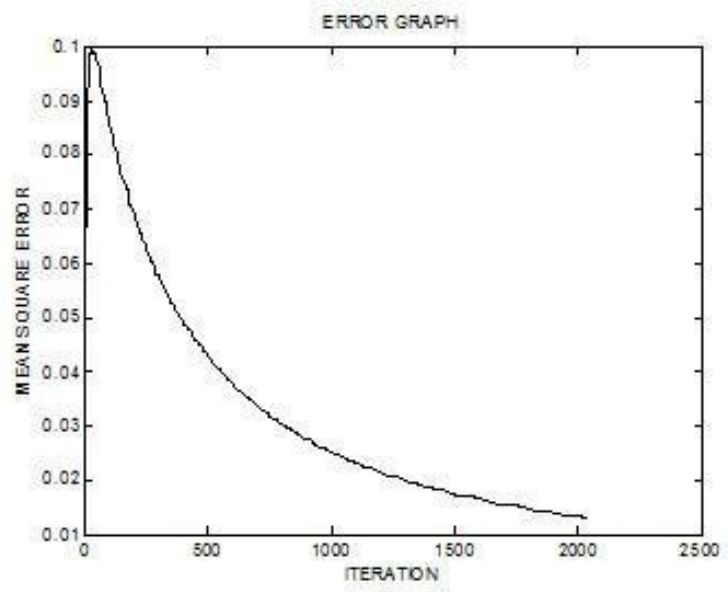

Figure 7. VIANN Root Mean Square Error Graph

\subsection{Results of the Images}

VIANN results for the trained image sets are found to be prosperous and encouraging. The identification rate for the suggested intelligent system, VIANN yielded $88 \%$ correct identification rate. 16 images out of the available 18 sites spectrums correctly yielded. As it can be seen from the results of the iterations using the Super computer, VIANN finalized the training after 2042 iterations within 55 seconds. Additionally, hidden layer nodes, learning rates, and momentum rates for VIANN has been obtained after several experiments. Figure 7 shows the RMS Error graph for the suggested neural network.

Experiments reveal that obtained data can be play a great role to gain time for determining the sensitive zones. In the field studies it is important to know reliable values of the site in terms of amplitude and frequency. Therefore VIANN system may give better results for produced graphics by HVSR method.

\subsection{Conclusion and Future Work}

In this paper, a fast assessment for the HVSR spectrums of microtremor records was developed. The suggested new approach is based on artificial neural networks. Decision parameter is selected as vulnerability index values. According to this mostly displacement sensitive zone, then velocity sensitive zone and acceleration sensitive zone discovered in the study area.

The robustness in the developed system is to stimulate the human visual inspection that usually highlights or notice the presence of peak amplitudes greater than 2 in the spectrum of whole data can be directly selected by the first look. Likewise, the system marks the higher values at different frequencies directly in 0.02 seconds that makes our system robust and effective.

The images used in testing phase of the proposed system are collected from two databases. 50 images has been considered as 25 normal and 25 abnormal. The experimental results obtained when testing the proposed system proved that the developed of the separation of risky zones system is a robust image processing system that is capable of deciding which sensitivity zones has high values of vulnerability index from the records of microtremor data. 
Studies were made at 100 different sites at Nicosia, Cyprus and these studies will be revised soon and will be increased. VIANN will be applied for different regions such as Izmir, Turkey, where has a complex geology. We will apply this technique to prove VIANN technique's feasibility.

\section{ACKNOWLEDGEMENTS}

This study was supported by The Scientific Research Support Unit of Near East University. The results of this study constitute a part of Hilmi Dindar's PhD thesis at the Institute of Natural and Applied Sciences in Dokuz Eylül University.

\section{REFERENCES}

Adeli, H., 2001. Neural networks in civil engineering: 19892000. Computer- Aided Civil Infrastructure Engineering, 16, pp. 126-142.

Atalar, C. and Das, B., 2009. Geotechnical properties of Nicosia soils, Cyprus, Proceedings 2nd ICNDSMGE, Near East University, Nicosia, North Cyprus, pp.360-367.

Atalar, C., 1999. Recent Earthquakes in North Cyprus, Book of Abstracts of International Conference on Earthquake Hazard and Risk in the Mediterranean Region, Lefkoşa, North Cyprus, 189.

Beroya, M. A., Aydin, A., Tiglao, R., and Lasala, M., 2009. Use of microtremor in liquefaction hazard mapping. Eng Geo., 107, pp. $140-153$.

Choobbasti, A. J., Rezaei, S., Farrokhzad, F. and Azar P., 2014. Evaluation of site response characteristics using nonlinear method (Case study: Babol, Iran), Frontiers of Structural and Civil Engineering, 8, pp.69-82.

Dimililer, K., 2012. Neural Network Implementation for X-Ray Image Compression. Electronics World, ISSN 1365-4675, Vol. 118, No. 1911, pp. 26-29

Dimililer, K., 2013. Back Propagation Neural Network Implementation for Medical Image Compression. Journal of Applied Mathematics, Volume 2013, pp. 1-8.

Dimililer, K., Ever, Y. K. and Ratemi, H., 2016. Intelligent Eye Tumour Detection System. Procedia Computer Science, 102, pp. 25-332.

Dimililer, K. and İlhan, A., 2016. Effect of Image Enhancement on MRI Brain Images with Neural Networks, Procedia Computer Science, 102, pp. 39-44.

Dimililer, K., Ever, Y. K., and Ergun, F., 2017. A Preliminary Framework using BPNN for Performability Modelling and Analyses of a Kerberos Server (ICACCI2017). $6^{\text {th }}$ International Conference on Advances Computing, Communications and Informatics, Karnataka, India, September 2017.

Esposito, A. M., Giudicepietro, F., Scarpetta, S., D’Auria, L., Marinaro, M. and Martini, M., 2006. Automatic Discrimination among Landslide, Explosion-Quake, and Microtremor Seismic Signals at Stromboli Volcano Using Neural Networks. Bulletin of the Seismological Society of America, 96, pp. 1230-124.

Fnais, M. S., Abdelrahman, K. and Al-Amri, A. M., 2010. Microtremor measurements in Yanbu city of Western Saudi Arabia: A tool for seismic microzonation. J King Saud Univ., 22, pp. $97-110$.

http://www.geopsy.org/download.php (3 Aug. 2007)
Gosar, A., 2007. Microtremor HVSR study for assessing site effects in the Bovec basin (NW Slovenia) related to 1998 Mw5.6 and 2004 Mw 5.2 earthquakes. Engineering Geology, 91, pp.178-193.

Günaydın, K. and Günaydın, A., 2008. Peak Ground Acceleration Prediction by Artificial Neural Networks for North Western Turkey, Hindawi Publishing Corporation Mathematical Problems in Engineering, 2008, pp.20

Hardesty, K., Wolf, L. W. and Bodin, P., 2010. Noise to signal: A microtremor study at liquefaction sites in the New Madrid Seismic Zone. Geophysics, 75(3), B83-B90.

Ishihara, K., 1978. Introduction to Dnyamic Soil Mechanism, January 1978

Jiyang, G., Gao, Y. and Wu, G., 2016. The nature frequency identification of tunnel lining based on the microtremor method, 1, pp. 108-113.

Kanai, K., Tanaka, T. and Osada, K., 1954. Measurement of Microtremors. Bulletin of Earthquake Research Institute, Tokyo University32, pp.199-210.

Kanai, K. and Tanaka, T., 1961. On microtremors VIII. Bulletin of Earthquake Research Institute, Tokyo University, 32, pp. 99114.

Kerh, T. and Chu, D., 2002. Neural networks approach and microtremor measurements in estimating peak ground acceleration due to strong motion, Advances in Engineering Software, 33, pp. 733-742.

Mucciarelli, M., Contri, P., Monachesi, G., Calvano, G. and Gallipoli M., 2001. An empirical method to assess the seismic vulnerability of existing buildings using the HVSR technique. Springer Pure and Applied Geophysics, 158, pp. 2635-2647.

Nakamura, Y., 1989. A method for dynamic characteristics estimation of subsurface using microtremor on the ground surface. Quarterly Report of Railway Technical Research Institute, 30, pp. 25-33.

Nakamura, Y., 1997. Seismic Vulnerability Indices for Ground and Structures Using Microtremor. World Congress on Railway Research, Florence.

Nogoshi, M. and Igarashi, T., 1970. On the propagation characteristics of microtremor. Journal Seismological Society, 23, pp. 264-280.

Özdağ, Ö. C., Akgün, M., Pamuk, E. and Kırnıç, E., 2016. Investigation of soil by geophysical methods in scope of earthquake-soil-structure common behaviour: A case study for Balçova/Izmir). DEÜ Journal of Science and Engineering 3, pp. 652-668, in Turkish.

Özdağ, Ö.C., Gönenç, T. and Akgün, M., 2015. Dynamic amplification factor concept of soil layers: a case study in İzmir (Western Anatolia). Arabian Journal of Geosciences, 8, pp. 10093-10104.

Pamuk, E., Akgün, M., Özdağ, Ö. C. and Gönenç, T., 2017a. 2D soil and engineering-seismic bedrock modelling of eastern part of Izmir inner bay/Turkey. Journal of Applied Geophysics, 137, pp. 104-117. 
Pamuk, E., Özdağ, Ö. C., Özyalın, .Şand Akgün, M., 2017b. Soil Characterization of Tinaztepe Region (Izmir/Turkey) using Surface Wave Methods and Nakamura (HVSR) technique. Earthquake Engineering and Engineering Vibration, in press

Paudyal, Y. R., Yatabe, R., N. Bhandary, N. P. and Dahal, R. K., 2013. Basement topography of the Kathmandu Basin using microtremor observation, Journal of Asian Earth Sciences 62, pp. $627-637$.

Stanko, G., Markušć S., Strelec, S. and Gazdek, M., 2017. HVSR analysis of seismic site effects and soil-structure resonance in Varað̌in city (North Croatia). Soil Dynamics and Earthquake Engineering, 92, pp. 666-677.

Tarabusi, G. and Caputo, R., 2017. The use of HVSR measurements for investigating buried tectonic structures: the Mirandola anticline, Northern Italy, as a case study. Int J Earth Sci (GeolRundsch), 106, pp. 341-353.

Tavakoli, H. and Kutanaei, S., 2014. Evaluation of effect of soil characteristics on the seismic amplification factor using the neural network and reliability concept. Arab J Geosci, 8, pp. 3881-3891.

Tuğsal, Ü.M., Kara, F.İ., Taşkın, B. and Sezen, A., 2007. Two empirical relations for calculating the target displacements considering Turkish earthquakes, Sixth National Conference on Earthquake Engineering, Istanbul, Turkey, pp. 119-130. 